\title{
IDENTIFIKASI BATUAN DASAR DAERAH PANTAI LUMPUE KOTA PAREPARE MENGGUNAKAN METODE GEOLISTRIK KONFIGURASI WENNER
}

\author{
Iswar Edis Pratama, Indra Jaya Muhtar, Syamsuddin*, Sabrianto Aswad \\ Departemen Geofisika, Fakultas MIPA, Universitas Hasanuddin, Makassar \\ *Penulis koresponden. Alamat email: syamsuddinmalang @yahoo.co.id
}

\begin{abstract}
Abstrak
Telah dilakukan penelitian untuk memperoleh informasi mengenai posisi dan kondisi perlapisan batuan dasar (bedrock) di sekitar Pantai Lumpue, Kota Pare-Pare, Sulawesi Selatan dengan menggunakan metode geolistrik resistivitas. Dengan adanya informasi mengenai perlapisan batuan dan kedalaman bedrock, dapat digunakan sebagai informasi pendukung saat melakukan pembangunan, serta memberikan gambaran tentang jenis batuan yang ada di daerah penelitian. Berdasarkan hasil pengukuran 2D geolistrik tahanan jenis konfigurasi Wenner, didapatkan nilai resitivitas berkisar antara $0,91 \Omega \mathrm{m}-514 \Omega \mathrm{m}$, dengan bedrock berupa batuan beku trakit dengan kedalaman bervariasi antara $2,5 \mathrm{~m}-24 \mathrm{~m}$.
\end{abstract}

Kata Kunci: Resistivitas, Wenner, Bedrock, Lumpue.

\begin{abstract}
Research has been carried out to obtain information about the position and condition of bedrock around Lumpue Beach, Pare-Pare City, South Sulawesi by using the resistivity geoelectric method. With information on rock lining and bedrock depth, it can be used as supporting information when do development, and provide an overview of the types of rocks in the research area. Based on the results of measurements of 2D geoelectric resistance with wenner configuration, is obtained the value of resistance ranged from $0.91 \Omega \mathrm{m}-514 \Omega \mathrm{m}$, with bedrock in the form of frozen rock trachyte with depths varying between $2.5 \mathrm{~m}-24 \mathrm{~m}$.
\end{abstract}

Keywords: Resistivity, Wenner, Bedrock, Lumpue.

\section{Pendahuluan}

Lapisan tanah suatu daerah tergantung dari kondisi geologi dan iklim. Hal tersebut mengakibatkan kondisi struktur lapisan tanah di Pantai Lumpue beraneka ragam. Untuk mengetahui jenis lapisan batuan tersebut, maka dilakukan dengan mencari nilai resistivitas bawah permukaan dengan menggunakan metode geolistrik tahanan jenis. Dengan adanya informasi mengenai perlapisan batuan dan kedalaman bedrock, dapat digunakan sebagai informasi pendukung saat melakukan pembangunan, serta memberikan gambaran tentang jenis batuan yang ada di daerah penelitian 
Metode geolistrik merupakan metode yang digunakan untuk mengetahui sifat aliran listrik di dalam bumi dengan cara mendeteksinya di permukaan bumi. Pendeteksian ini meliputi pengukuran potensial, arus dan medan elektromagnetik yang terjadi baik secara injeksi maupun secara alamiah. Salah satu metode yang digunakan untuk mempelajari kondisi geologi bawah permukaan adalah geolistrik tahanan jenis. Metode ini telah banyak digunakan dan hasilnya cukup baik (Loke, 2004).

Hukum Ohm yang pertama kali dicetuskan oleh George Simon Ohm, menyatakan bahwa beda potensial yang timbul di ujung-ujung suatu medium berbanding lurus dengan arus listrik yang mengalir pada medium tersebut. Selain itu, dia juga menyatakan bahwa tahanan listrik berbanding lurus dengan panjang medium dan berbanding terbalik dengan luas penampangnya. Formulasi dari kedua pernyataan Ohm di atas, dapat dituliskan sebagai berikut:

$$
\begin{aligned}
& V \infty I \text { atau } V=I \cdot R \\
& R \propto \frac{L}{A} \text { atau } R=\rho \frac{L}{A}
\end{aligned}
$$

Prinsip pelaksanaan survei resistivitas adalah mengalirkan arus listrik searah ke dalam bumi melalui dua elektroda arus yang ditancapkan pada dua titik permukaan tanah dan kemudian mengukur respon beda potensial yang terjadi antara dua titik yang lain di permukaan bumi dimana dua elektroda potensial ditempatkan dalam suatu susunan tertentu (Syamsuddin, 2007).

Dalam pendugaan resistivitas, digunakan asumsi-asumsi sebagai berikut:

1. Pada bawah permukaan bumi terdiri dari lapisan-lapisan dengan ketebalan tertentu, kecuali pada lapisan terbawah yang mempunyai ketebalan tidak berhingga.
2. Bidang batas antar lapisan adalah horizontal.

3. Setiap lapisan dianggap homogen isotropis.

Apabila pada medium homogen isotropis dialiri arus searah (I) dengan medan listrik (E), maka elemen arus (dI) yang melalui suatu elemen luasan $(\mathrm{dA})$ dengan rapat arus $(\mathrm{J})$ akan berlaku hubungan:

$$
d I=\bar{J} \cdot d \bar{A}
$$

dengan demikian rapat arus $(\bar{J})$ di setiap elemen luasan akibat medan listrik $(\bar{E}=$ $-\nabla \bar{V})$, akan memenuhi hubungan sebagai berikut:

$$
\bar{J}=-\sigma \nabla \bar{V}
$$

Apabila arus stasioner dengan koefisien konduktivitas konstan, maka akan diperoleh persamaan Laplace dengan potensial harmonis (Telford et al., 1990).

$$
\nabla^{2} V=0
$$

Metode geolistrik mengidentifikasi beda potensial yang diukur di permukaan. Pengukuran potensial menggunakan dua elektroda potensial dan dua elektroda arus yang disusun sedemikian sehingga membentuk suatu konfigurasi (Gambar. 1).

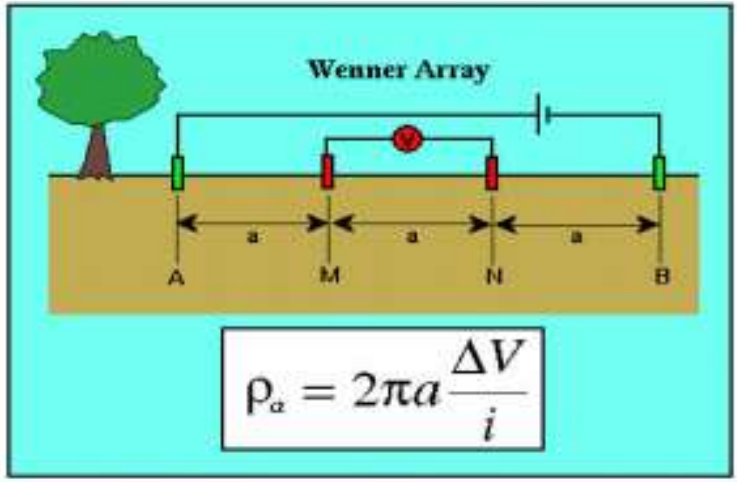

Gambar 1. Susunan elektroda konfigurasi Wenner (Telford et al., 1990).

Dalam konfigurasi ini diketahui bahwa $\mathrm{AM}=$ $\mathrm{BN}=\mathrm{a}$, sehingga harga faktor geometri dan resistivitas semu menjadi: 


$$
\begin{array}{r}
\rho_{a w}=2 \pi a \frac{\Delta V}{I} \\
K_{w}=2 \pi a
\end{array}
$$

Survei resistivitas memberikan gambaran distribusi resistivitas bawah permukaan. Untuk mengkonversi gambaran resistivitas bawah permukaan menjadi sebuah gambaran geologi maka pengetahuan untuk membedakan tipe dari material bawah permukaan dan kenampakan geologinya berdasarkan nilai resistivitasnya sangat dibutuhkan (Telford et al., 1990).

Tabel 1 Nilai resistivitas material material Bumi

\begin{tabular}{|c|c|}
\hline Rock Type & $\begin{array}{c}\text { Resistivity Range } \\
(\mathbf{\Omega m})\end{array}$ \\
\hline Granite & $3 \times 10^{2}-10^{6}$ \\
\hline Granite Porphyry & $\begin{array}{l}4.5 \times 10^{3} \text { (wet) }- \\
1.3 \times 10^{6}(\text { dry }) \\
\end{array}$ \\
\hline Feldspar Porphyry & $4 \times 10^{3}$ (wet) \\
\hline Albite & $\begin{array}{l}3 \times 10^{2}(\text { wet })- \\
3.3 \times 10^{3}(\text { dry })\end{array}$ \\
\hline Syenite & $10^{2}-10^{6}$ \\
\hline Diorite & $10^{4}-10^{5}$ \\
\hline Diorite Porphyry & $\begin{array}{l}1.9 \times 10^{3}(\text { wet })- \\
2.8 \times 10^{4}(\text { dry })\end{array}$ \\
\hline Porphyryte & $\begin{array}{l}10-5 \times 10^{4}(\text { wet })- \\
3.3 \times 10^{3}(\text { dry })\end{array}$ \\
\hline Carbonatized Porphyry & $\begin{array}{l}2.5 \times 10^{3}(\text { wet })- \\
6 \times 10^{4}(\text { dry })\end{array}$ \\
\hline Quartz Porphyry & $\begin{array}{l}3 \times 10^{2}(\text { wet })- \\
9 \times 10^{5}(\text { dry })\end{array}$ \\
\hline Quartz Diorite & $\begin{array}{l}2 \times 10^{4}-2 \times 10^{6}(\text { wet })- \\
1.8 \times 10^{5}(\text { dry })\end{array}$ \\
\hline Porphyry (Various) & $60-10^{4}$ \\
\hline Dacite & $2 \times 10^{4}$ (wet) \\
\hline Andesite & $\begin{array}{l}4.5 \times 10^{4} \text { (wet) }- \\
1.7 \times 10^{5} \text { (dry) } \\
\end{array}$ \\
\hline Diabase Porphyry & $\begin{array}{l}10^{3}(\text { wet })- \\
1.7 \times 10^{5} \text { (dry) }\end{array}$ \\
\hline Diabase (various) & $20-5 \times 10^{7}$ \\
\hline Lavas & $10^{2}-5 \times 10^{4}$ \\
\hline Gabbro & $10^{3}-10^{6}$ \\
\hline
\end{tabular}
(Telford et al., 1990).

\begin{tabular}{|r|l|}
\hline Basalt & $10-1.3 \times 10^{7}($ dry $)$ \\
\hline Olivine Norite & $10^{3}-6 \times 10^{4}($ wet $)$ \\
\hline Peridotite & $3 \times 10^{3}($ wet $)-$ \\
$6.5 \times 10^{3}($ dry $)$
\end{tabular}

\section{Metode Penelitian}

Penelitian ini dilakukan Pantai Lumpue, Kelurahan Lumpue, Kecamatan Bacukiki, Kota Pare-Pare, Sulawesi Selatan. Penelitian dilakukan dengan menggunakan metode geolistrik 2D Konfigurasi Wenner. Setelah pengambilan data selanjutnya dilakukan pengolahan data dengan Software Res2DInv sehingga dihasilkan penampang resistivitas yang selanjutnya diinterpretasi dengan bantuan data geologi.

\section{Hasil dan Pembahasan}

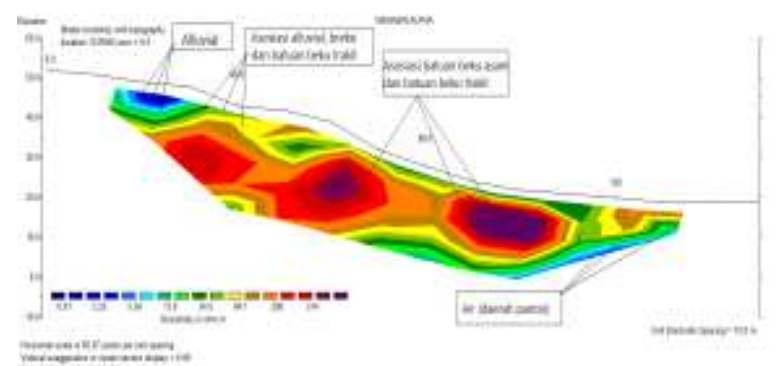

Gambar 2. Penampang resistivitas hasil pergambilan dan pengolahan data. 
Berdasarkan nilai resistivitas dan geologi maka daerah Lumpue diperkirakan memiliki lithologi sebagai berikut:

- Pada panjang lintasan mulai dari $15 \mathrm{~m}$ $20 \mathrm{~m}$ dengan kedalaman 2,5 $\mathrm{m}-5 \mathrm{~m}$ ditunjukkan dengan warna biru tua hingga biru muda dengan nilai resistivitas 0,91 $\Omega \mathrm{m}-5,56 \Omega \mathrm{m}$ diinterpretasikan sebagai alluvial.

- Gradasi warna hijau muda sampai kuning pada bentangan $35 \mathrm{~m}-150 \mathrm{~m}$ dan kedalaman mulai dari $7,5 \mathrm{~m}-12,8 \mathrm{~m}$ memiliki nilai resisitivitas sebesar 13,8 $\Omega \mathrm{m}-84,1 \Omega \mathrm{m}$ yang diinterpretasikan sebagai asosiasi antara breksi vulkanik dan batuan beku trakit.

- Gradasi warna kuning sampai coklat pada bentangan $25 \mathrm{~m}-110 \mathrm{~m}$ dan $120 \mathrm{~m}$ dan $150 \mathrm{~m}$ dan kedalaman 2,5 m - $11 \mathrm{~m}$ memiliki nilai resistivitas sebesar 84,1 $\Omega \mathrm{m}-208 \Omega \mathrm{m}$ yang diinterpretasikan sebagai batuan beku trakit.

- Gradasi warna merah sampai ungu pada bentangan $29 \mathrm{~m}-110 \mathrm{~m}$ dan kedalaman 5 $\mathrm{m}-24,7 \mathrm{~m}$ memiliki nilai resistivitas sebesar $208 \Omega \mathrm{m} \quad->514 \Omega \mathrm{m}$ diinterpretasikan sebagai asosiasi antara batuan beku trakit dengan batuan breksi vulkanik yang memiliki struktur yang kompak sehingga memiliki nilai resistvitas paling tinggi.

\section{Kesimpulan}

Berdasarkan hasil pengukuran geolistrik resistivitas yang telah dikorelasikan dengan geologi lokal daerah Lumpue dan singkapan batuan yang terdapat di lokasi pengukuran, maka batuan dasar diperkirakan sebagai batuan beku trakit dan breksi vulkanik dengan resistivitas sekitar 13,8 $\Omega \mathrm{m}-84,1$ $\Omega \mathrm{m}$ dan terletak pada kedalaman bervariasi mulai $2,5 \mathrm{~m}-24,7 \mathrm{~m}$.

\section{Daftar Pustaka}

Loke, M.H. 2004. Electrical Imaging Surveys for Environmental and Engineering Studies.

Syamsuddin. 2007. Penentuan struktur bawah permukaan bumi dangkal dengan menggunakan metoda Geolistrik tahanan Jenis 2D (Studi kasus potensi tanah longsor di Panawangan, Ciamis). Tesis, Institut Teknologi Bandung.

Telford, W.M., Geldart, L.P., Sheriff, R.E., Keys, D.A. 1990. Applied Geophysics. Cambridge University Press: London. 